\title{
Extração da Lignina e Emprego da Mesma em Curvas de Calibração para a Mensuração da Lignina em Produtos Vegetais ${ }^{1}$
}

\author{
Romualdo Shigueo Fukushima², Geraldo Garippo ${ }^{3}$, Ana Mônica Quinta Barbosa Habitante ${ }^{4}$, \\ Roseli Sengling Lacerda ${ }^{4}$
}

\begin{abstract}
RESUMO - O objetivo deste experimento foi a extração da lignina e seu uso nas curvas de calibração para determinar a concentração de lignina em produtos vegetais. Dentre os métodos analíticos utilizados para a mensuração da lignina, pode-se mencionar o método "lignina solúvel em brometo de acetila - LSBA", no qual a lignina é solubilizada em uma solução de brometo de acetila a $25 \%$ em ácido acético glacial e, depois, lida no comprimento de onda a $280 \mathrm{~nm}$. Entretanto, todo método espectrofotométrico requer o emprego de um padrão de referência confiável; neste experimento utilizou-se como padrão de referência a lignina da planta forrageira extraída com o emprego do próprio brometo de acetila. Quantificou-se a lignina presente em quatro amostras de forrageiras, em dois estádios de maturidade e, ainda, em duas amostras de madeiras, comparando-se os dados com outros dois métodos de determinação da lignina (lignina em detergente ácido - LDA e lignina permanganato de potássio - LPer). Os três métodos não foram concordantes entre si, sendo que, para praticamente todas as amostras, o método da LSBA mostrou valores mais elevados que os outros dois métodos. Para cada amostra analisada, foram confeccionados uma curva-padrão e um espectrograma na faixa de comprimento de luz de 240 a $320 \mathrm{~nm}$. A análise dessas curvas e dos espectrogramas indicou diferenças qualitativas entre as amostras, em função não apenas da espécie botânica, mas também do estádio de maturidade da planta.
\end{abstract}

Palavras-chave: análise química, espectrofotometria, lignina, plantas forrageiras

\section{Lignin Extraction and its Performance in Calibration Curves to Determine Lignin Concentration in Plants}

\begin{abstract}
The objective of this experiment was the extraction of lignin and its use in the calibration curves to determine lignin concentration in vegetable plants. Among the analytical methods for measuring lignin concentration, there is the "acetyl bromide soluble lignin -ABSL" method, were solubilized lignin in $25 \%$ solution of acetyl bromide in glacial acetic acid is read at $280 \mathrm{~nm}$. However, any spectrophotometric method requires a reliable standard to which optical density readings are compared; in this experiment, the standard was obtained through extraction with acetyl bromide reagent. Lignin was quantified in four forage samples, at two maturity stages, and also in two wood samples, comparing the obtained data with two other analytical methods for lignin (acid detergent lignin - ADL and potassium permanganate lignin - PerL). The three techniques yielded different values for the same samples; in general, the ABSL method showed higher lignin concentrations than the two other methods. For each sample it was made a standard curve and a 240-320 nm ultraviolet scanning. Analyses of such curves and scannings indicated qualitative differences among samples, not only related to plant species, but also to maturity stage of vegetable samples.
\end{abstract}

Key Words: chemical analysis, forages, lignin, spectrophotometric analysis

\section{Introdução}

A lignina é um componente não-carboidrato da parede celular dos vegetais, normalmente considerada indigestível e também inibidora da digestibilidade da parede celular das plantas forrageiras, acentuando a sua ação, à medida que o vegetal amadurece.

Entre os diversos métodos laboratoriais de mensuração da lignina, está o método espectrofotométrico, que se baseia no fato de a lignina ser solúvel em solução de brometo de acetila a $25 \%$ em ácido acético glacial, sendo, em seguida, lida a absorbância da mesma no comprimento de onda a $280 \mathrm{~nm}$ (MORRISON, 1972). Entretanto, existe um entrave - a ausência de um padrão de referência -, pois todo método espectrofotométrico pressupõe a existência de um padrão (FENGEL e WEGENER, 1989). Recentemente, FUKUSHIMA e DEHORITY (no prelo) propuseram um padrão, a lignina extraída da planta pelo reagente brometo de acetila, e lograram

\footnotetext{
1 Parte de um projeto de pesquisa financiado pela Fundação de Amparo à Pesquisa do Estado de São Paulo (FAPESP) processo no 95/3798-3.

2 Professor Associado da Faculdade de Zootecnia e Engenharia de Alimentos da Universidade de São Paulo (FZEA-USP), Av. Duque de Caxias Norte, 225 - 13630-000 - Pirassununga, SP. E.mail: rsfukush@usp.br; E.mail atual: rsf@dfrc.wisc.edu

3 Discente do curso de graduação em Zootecnia da FZEA-USP. Bolsista de Iniciação Científica da FAPESP.

4 Técnica de Nível Superior da FZEA-USP.
} 
resultados animadores na quantificação do teor de lignina em algumas plantas forrageiras.

Existem diferenças entre as ligninas presentes em espécies botânicas diversas (FENGEL e WEGENER, 1989); também constatou-se a presença de diferentes frações de lignina em determinada amostra (CURVELO, 1992); entretanto, diferenças entre ligninas provenientes de plantas em diferentes fases de maturidade não têm sido descritas. É possível que alterações estruturais, em função do grau de maturidade da planta, também estejam relacionadas com o declínio da digestibilidade da parede celular.

No presente trabalho, objetivou-se avaliar o método espectrofotométrico "lignina solúvel em brometo de acetila", empregando como padrão de referência a lignina extraída da própria planta, comparando-a com outros dois métodos analíticos para a determinação da lignina, a lignina em detergente ácido e a lignina permanganato de potássio, de algumas espécies forrageiras em dois estádios de maturidade, incluindo dois tipos de madeira, e estimar a correlação existente entre metodologia e digestibilidade in vitro das amostras vegetais. Como é possível o surgimento de alterações estruturais na lignina, à medida que a planta forrageira amadurece, e estas alterações se refletirem na intensidade de absorção da luz ultra-violeta, a pesquisa também objetivou comparar as ligninas extraídas por intermédio de espectrogramas, obtidos no comprimento de onda de 240 a $320 \mathrm{~nm}$.

\section{Material e Métodos}

Foram ensaiadas as seguintes plantas forrageiras: alfafa (Medicago sativa), aveia (Avena sativa), braquiária (Brachiaria decumbens) e colonião (Panicum maximum cv. colonião); além disso, estudaram-se também as madeiras pinheiro (Pinus sp) e eucalipto (Eucalyptus sp). Para o estudo objetivando verificar a possibilidade de se empregar a curva de regressão da alfafa para estimar o conteúdo de lignina em outras espécies forrageiras (gramíneas), foi analisado outro grupo de plantas: aveia (Avena sativa), centenário ( $P$. maximum cv. centenário), colonião ( $P$. maximum $\mathrm{cv}$. colonião), bermuda (Cynodon dactylum), estrela (Cynodon plectostachyus), napier (Pennisetum purpureum Schumm) e setária (Setaria anceps cv. nandi). De acordo com HATFIELD (comunicação pessoal), teoricamente, não deveriam existir quaisquer problemas em se empregar a curva de regressão da alfafa, para estimar a concentração de lignina em outras plantas forrageiras, incluindo-se as gramíneas, uma vez que se infere que, mesmo na ocorrência de mudanças na composição fenólica entre moléculas de lignina de diferentes espécies vegetais, esse fenômeno não seria suficiente para alterar a intensidade de absorção da luz ultravioleta. Quanto ao estádio de maturidade, adotou-se o seguinte critério: plantas jovens foram aquelas que ainda não apresentavam inflorescência plena (fase de emergência da panícula ou início da abertura das primeiras flores) e plantas maduras, aquelas que apresentavam sementes formadas e menos que a metade de folhas verdes. Estes materiais foram provenientes do campo agrostológico do Departamento de Zootecnia da Faculdade de Zootecnia e Engenharia de Alimentos da Universidade de São Paulo (FZEA-USP); as amostras de madeiras (serragem) vieram da marcenaria do Campus da USP de Pirassununga. As amostras foram secas em estufa a $65^{\circ} \mathrm{C}$, com ventilação forçada por três dias, moídas em moinho laboratorial (Wiley) com peneira de 1,0 $\mathrm{mm}$ e acondicionadas em frascos de vidro.

A preparação de parede celular foi obtida de acordo com a descrição de IIYAMA e WALLIS (1990), com a exceção de que, no presente trabalho, houve uma etapa adicional inicial, que consistiu na infusão da amostra em água a $90^{\circ} \mathrm{C}$ por $45 \mathrm{~min}$, sendo, após, filtrada em cadinho de vidro com filtro de porcelana, porosidade grossa (40-60 micra). Em seguida, a amostra foi refluxada seqüencialmente em solução de álcool etílico a 90\% e clorofórmio, por duas horas cada solvente, utilizando-se aparelho Soxhlet. A amostra foi seca em estufa ventilada a $65^{\circ} \mathrm{C}$ por 48 horas, anotando-se a concentração de parede celular.

O procedimento para a extração da lignina, empregando-se o reagente brometo de acetila (BrAc), é descrito a seguir: em dois gramas de parede celular, acondicionados em tubo de teflon com tampa de rosquear, foram pipetados seis mililitros de uma solução a $20 \%$ de ácido perclórico em ácido acético glacial e $20 \mathrm{~mL}$ de uma solução a $25 \%$ de brometo de acetila em ácido acético glacial; o tubo foi fechado, agitado e colocado em banho-maria a $70^{\circ} \mathrm{C}$ por 30 minutos, com agitação a cada $15 \mathrm{~min}$. Após a digestão, centrifugou-se este material a $3000 \mathrm{rpm}$ por 10 min. O sobrenadante foi invertido em um balão de dois litros e o resíduo, desprezado. O balão foi imerso em um banho de gelo e, após cerca de cinco minutos, inverteu-se sobre o sobrenadante aproximadamente dois litros de água destilada gelada, ocorrendo, assim, 
1304 Rev. bras. zootec.

a precipitação da lignina. Esta foi separada por meio de filtração a vácuo, com emprego de papel-filtro Whatman $\mathrm{n}^{\circ} 4$, lavado com $300 \mathrm{~mL}$ de água destilada, e submetido à parcial desidratação em estufa ventilada ajustada a $45^{\circ} \mathrm{C}$. Este precipitado foi solubilizado em $50 \mathrm{~mL}$ de dioxana, e novamente adicionada água destilada (cerca de um litro), por onde obteve-se a formação de uma solução de aspecto coloidal; adição de dois gramas de sulfato de sódio anidro promoveu a floculação da lignina. A seguir, este precipitado foi filtrado, lavado e parcialmente desidratado, sendo em seguida novamente solubilizado em dioxana, como descrito anteriormente. A recuperação da lignina deu-se por gotejamento desta solução em éter etílico anidro/ éter de petróleo (80:20), sob constante agitação. Após filtração por meiode uma membrana de náilon (porosidade 0,45 micra), o resíduo foi lavado com $40 \mathrm{~mL}$ de éter de petróleo e, após secagem em estufa ventilada a $45^{\circ} \mathrm{C}$, obteve-se a lignina brometo de acetila ( $\mathrm{LBrAc})$.

Para a confecção das curvas padrão, uma para cada lignina extraída, adotou-se o seguinte procedimento: $30 \mathrm{mg}$ de LBrAc (feitas as devidas correções para os teores de carboidrato e de proteína) foram colocados em um tubo de teflon, ao qual foram acrescentados $0,8 \mathrm{~mL}$ da solução de ácido perclórico e quatro mililitros da solução de brometo de acetila. Um tubo branco também foi preparado. Os tubos foram agitados e aquecidos a $70^{\circ} \mathrm{C}$ por $30 \mathrm{~min}$ em banho-maria. Após resfriados, completou-se o volume para $30 \mathrm{~mL}$ com ácido acético glacial. Em dez tubos de vidro já contendo seis mililitros de ácido acético e quatro mililitros de solução de hidróxido de sódio $0,3 \mathrm{~N}$, foram adicionadas alíquotas em volumes crescentes, provenientes do tubo contendo a $\mathrm{LBrAc}$, resultando, dessa maneira, em concentrações crescentes de lignina. Completou-se o volume para $24 \mathrm{~mL}$ com ácido acético glacial. Adicionou-se $1 \mathrm{~mL}$ da solução $0,5 \mathrm{M}$ de cloridrato de hidroxilamina. Os tubos foram agitados e as respectivas densidades ópticas (absorbâncias), lidas em espectrofotômetro (Milton Roy, modelo Genesis II), no comprimento de onda a $280 \mathrm{~nm}$.

Também foram traçados espectrogramas para cada amostra de LBrAc, na faixa de 240 a $320 \mathrm{~nm}$, mantendo-se a concentração da lignina constante para todas as varreduras. Espectrogramas de uma mesma planta, em estádios de maturidade diferentes, bem como espectrogramas de diferentes plantas, foram confrontados para se avaliarem possíveis diferenças de densidade óptica destas amostras.

Para a mensuração final da lignina nas amostras, em $150 \mathrm{mg}$ de parede celular, foram adicionados $0,5 \mathrm{~mL}$ da solução de ácido perclórico e $2,5 \mathrm{~mL}$ da solução de brometo de acetila, e os tubos, incubados a $70^{\circ} \mathrm{C}$ por $30 \mathrm{~min}$. A seguir, quantidade suficiente para $30 \mathrm{~mL}$ foi completada com ácido acético glacial, retirando-se uma alíquota de $1 \mathrm{~mL}$ desta solução para um tubo já contendo $6 \mathrm{~mL}$ de ácido acético glacial e $4 \mathrm{~mL}$ de hidróxido de sódio 0,3 $\mathrm{M}$. Após adição de $1 \mathrm{~mL}$ de cloridrato de hidroxilamina 0,5 M, o volume foi completado para $25 \mathrm{~mL} \mathrm{com}$ ácido acético glacial. Foram realizadas as leituras de densidade óptica a $280 \mathrm{~nm}$, determinando-se a concentração final da lignina com base na equação de regressão obtida pelo traçado da respectiva curva padrão de cada LBrAc.

Para fins comparativos, outros dois métodos de mensuração da lignina foram conduzidos, o método da lignina em detergente ácido - LDA (VAN SOEST, 1963) e o da lignina em permanganato de potássio - LPer (VAN SOEST e WINE, 1968), ambos procedimentos analíticos de natureza gravimétrica. As determinações de proteína bruta nas amostras de $\mathrm{LBrAc}$ seguiram os preceitos da AOAC (1980) e as determinações de carboidrato, a técnica da antrona, descrita por VILES JR. e SILVERMAN (1949).

No ensaio de digestibilidade in vitro, as amostras (em duplicatas) foram incubadas em solução de MacDougall e líquido ruminal (1:1) e apenas a fase fermentativa foi conduzida (FUKUSHIMA et al., 1991) em um delineamento experimental de blocos ao acaso (STEEL e TORRIE, 1980), no qual os blocos ocorreram em três semanas consecutivas; o doador de líquido ruminal foi um bovino fistulado no rúmen recebendo dieta à base de volumoso (70 a $80 \%$ ), constituído de capim e canade-açúcar picados, mais concentrado (20 a 30\%). As comparações estatísticas referentes aos dados de lignina (em duplicata), provenientes dos três métodos analíticos, foram feitas pela análise de variância (ANOVA) e as diferenças entre as médias, determinadas pelo teste " $t$ " de Student, no nível de 5\%. Em virtude de o enfoque da pesquisa ter sido primordialmente sobre método analítico, não foram efetuadas outras comparações, como aspectos relativos a estádio de maturidade ou espécie botânica. Os dados de lignina provenientes dos três métodos foram correlacionados com os valores de digestibilidade in vitro da matéria seca das amostras 
vegetais. Os dados foram analisados com o auxílio do pacote estatístico SAS (STATISTICAL ANALYSIS SYSTEM - SAS, 1985).

\section{Resultados e Discussão}

$\mathrm{O}$ rendimento da lignina brometo de acetila (LBrAc) na parede celular, bem como os seus teores de carboidrato, proteína $(\mathrm{N} \times$ 6,25) e cinzas, está mostrado na Tabela 1. Constam também os valores de rendimento de LBrAc, na base da planta inteira (matéria seca), após as correções para carboidrato e proteína. O rendimento de $\mathrm{LBrAc}$ na planta inteira foi de 1,1 a $25,6 \%$. FUKUSHIMA et al. (1991) extraíram lignina de amostras de alfafa, por meio de extração alcoólica (lignina nativa de Brauns), e o rendimento foi de menos de $1 \%$ da matéria seca. ROSSINI et al. (1989) empregaram diversos solventes para extrair lignina da serragem da madeira Pinus caribaea hondurensis, obtendo de 2,0 a 6,6\% de rendimento. A obtenção de lignina foi melhorada, quando a extração foi catalisada por um ácido mineral, variando de 1,1 a 24,4\%, em relação ao peso seco da madeira (BALOGH et al., 1989).

As análises químicas das ligninas brometo de acetila revelaram teores de carboidrato $(\mathrm{CHO})$ das diversas LBrAc, variando de 11,2 (pinheiro) a 29,7\% (aveia) (Tabela 1). FUKUSHIMA (1989), ao examinar algumas formas de lignina "kraft", verificou a presença de 10,3 a 11,2\% de CHO, ao passo que a lignina nativa obtida da alfafa apresentou $15,5 \%$ de CHO. Obtenção de lignina relativamente pura em apreciáveis quantidades não é tarefa fácil (IIYAMA e WALLIS, 1990) e, possivelmente, uma das razões residiria no fato de a lignina ser covalentemente ligada à fração carboidrato da parede celular, particularmente a hemicelulose (MORRISON, 1973).

Com a exceção das LBrAc provenientes das madeiras, as demais apresentaram apreciáveis teores de proteína (PB); embora não tenha sido estabelecida prova química, existe proposta de que proteínas são covalentemente ligadas à molécula de lignina (WHITMORE, 1982). No presente trabalho, estes valores ficaram entre 4,9 (aveia madura) e $21,4 \%$ (colonião jovem), sendo que as plantas jovens exibiram teores mais elevados que as plantas maduras. Ligninas provenientes de gramíneas tenderam a apresentar menores teores de nitrogênio $(\mathrm{N})$ que a lignina de alfafa (HATFIELD et al., 1994); a parede celular de gramíneas contém menos $\mathrm{PB}$, sendo que uma parte das mesmas funciona como proteína estrutural
(DARVILL et al., 1980). Entretanto, a presente pesquisa revelou que a $\mathrm{LBrAc}$ extraída da braquiária madura continha maior teor de $\mathrm{PB}$ que a alfafa madura e, também, a concentração de PB do colonião jovem foi praticamente idêntica à da alfafa jovem. Apesar de a presente metodologia de extração da LBrAc, bem como as análises químicas referentes à mesma, ter sido razoavelmente estudada, dados aparentemente discrepantes como os supracitados devem ser encarados com a devida cautela. As ligninas de plantas forrageiras contêm $\mathrm{N}$, que é indisponível à digestão animal, enquanto as ligninas de madeira são essencialmente livres de N (VAN SOEST, 1994). Lavagem com água quente ou extração alcoólica de lignina "kraft" reduziu a concentração de $\mathrm{N}$ de 3,6 para 0,8 (FUKUSHIMA, 1989), o que poderia ser creditada à não existência de ligações químicas entre a lignina e proteína (MORRISON, 1973). A questão que ainda permanece é se o N é parte integrante da molécula de lignina ou se está presente na forma de proteína. Alguns dados de pesquisas evidenciaram a presença de proteínas (McDOUGALL et al., 1996), sendo a principal denominada de extensina, uma glicoproteína presente na parede celular dos vegetais, nos quais predominam os aminoácidos hidroxiprolina, lisina e serina (WILSON e FRY, 1986). Todas as preparações de LBrAc mostraram praticamente total ausência de matéria mineral, variando de 0 , para as amostras de madeira, a 1,1, para o colonião (Tabela 1).

Embora existam descritas na literatura diversas formas de se extrair lignina dos vegetais, deve-se ressaltar que os produtos resultantes dessas extrações podem ser diferentes das ligninas presentes nas plantas das quais se originaram (CURVELO, 1992). FENGEL e WEGENER (1989) afirmaram que uma das dificuldades encontradas na determinação espectrofotométrica é o fato de a lignina isolada poder absorver luz ultravioleta diferentemente da lignina presente na planta, originando, assim, interpretação errônea das leituras de densidade óptica. $\mathrm{Na}$ presente metodologia, o procedimento para a extração do padrão de referência é exatamente o mesmo empregado para a determinação analítica da lignina na amostra vegetal, o que pode eliminar o risco da lignina extraída ser diferente da lignina presente na amostra sendo analisada.

Para cada LBrAc extraída, foi traçada uma curva padrão. Valores de carboidrato e proteína foram devidamente considerados. Todas as curvas foram lineares nas concentrações testadas. A Figura 1, da 
1306 Rev. bras. zootec.

Tabela 1 - Rendimento de lignina brometo de acetila na parede celular, teores de carboidrato, proteína $(\mathrm{N} \times 6,25)$ e cinzas nas amostras de lignina brometo de acetila e rendimento de lignina brometo de acetila (após correção para teores de carboidrato e proteína) na planta inteira ${ }^{1}$

Table 1 - Acetyl bromide lignin yield on the cell wall; contents of carbohydrate, protein $(N \times 6.25)$ and ash in the acetyl bromide lignin samples and acetyl bromide lignin yield (after corrections for carbohydrate and protein contents) in the whole plant ${ }^{1}$

\begin{tabular}{|c|c|c|c|c|c|c|}
\hline $\begin{array}{l}\text { Amostra } \\
\text { Sample }\end{array}$ & $\begin{array}{l}\text { Est } \\
\text { Sta }\end{array}$ & $\begin{array}{l}\operatorname{LBrAc}(\mathrm{PC}) \\
\operatorname{AcBrL}(C W)\end{array}$ & $\begin{array}{l}\mathrm{CHO} \\
\mathrm{CHO}\end{array}$ & $\begin{array}{l}\mathrm{PB} \\
C P\end{array}$ & $\begin{array}{c}\mathrm{CZ} \\
\text { Ash }\end{array}$ & $\begin{array}{l}\operatorname{LBrAc}(\mathrm{PI}) \\
\operatorname{AcBrL}(W P)\end{array}$ \\
\hline \multirow{4}{*}{$\begin{array}{l}\text { Alfafa } \\
\text { Alfalfa }\end{array}$} & $\mathrm{J}$ & 7,6 & 16,6 & 21,1 & 0,5 & 2,7 \\
\hline & $Y$ & & & & & \\
\hline & $\mathrm{M}$ & 5,1 & 21,7 & 8,4 & 0,6 & 2,3 \\
\hline & $M$ & & & & & \\
\hline \multirow{4}{*}{$\begin{array}{l}\text { Aveia } \\
\text { Oats }\end{array}$} & $\mathrm{J}$ & 5,8 & 29,7 & 13,6 & 0,8 & 1,9 \\
\hline & $Y$ & & & & & \\
\hline & M & 17,2 & 19,8 & 4,8 & 0,8 & 9,2 \\
\hline & $M$ & & & & & \\
\hline \multirow{4}{*}{$\begin{array}{l}\text { Braquiária } \\
\text { Signal grass }\end{array}$} & $\mathrm{J}$ & 7,0 & 14,0 & 13,8 & 0,6 & 3,4 \\
\hline & $Y$ & & & & & \\
\hline & $\mathrm{M}$ & 2,2 & 19,5 & 11,3 & 0,8 & 1,1 \\
\hline & $M$ & & & & & \\
\hline \multirow{4}{*}{$\begin{array}{l}\text { Colonião } \\
\text { Guinea grass }\end{array}$} & $\mathrm{J}$ & 6,9 & 20,3 & 21,4 & 1,1 & 3,0 \\
\hline & Y & & & & & \\
\hline & M & 12,1 & 16,3 & 5,4 & 0,9 & 8,1 \\
\hline & $M$ & & & & & \\
\hline & - & 30,1 & 19,0 & 0,9 & 0,0 & 21,2 \\
\hline Eucalyptus & & & & & & \\
\hline Pinheiro & - & 33,5 & 11,2 & 0,7 & 0,0 & 25,6 \\
\hline \multicolumn{7}{|l|}{ Pine tree } \\
\hline Média & - & 12,7 & 18,8 & 10,1 & 0,6 & 7,8 \\
\hline \multicolumn{7}{|l|}{ Mean } \\
\hline & - & 10,63 & 4,96 & 7,30 & 0,36 & 8,47 \\
\hline
\end{tabular}

1 Valores na base da matéria seca e em porcentagem; Est - estádio de maturidade das amostras; $\mathrm{J}$ - jovem; M - maduro; LBrAc (PC) - lignina brometo de acetila na parede celular; $\mathrm{CHO}$ - carboidrato; PB - proteína bruta; CZ - cinzas; LBrAc (PI) - lignina brometo de acetila na planta inteira.

1 Data on a dry matter basis and in percentage; Sta - maturity stage of samples; $Y$ - young; $M$ - mature; AcBrL (CW) - acetyl bromide lignin in the cell wall; $C H O$ - carbohydrate; $C P$ - crude protein; $A c B r L(W P)$ - acetyl bromide lignin in the whole plant.

aveia (A - jovem e B - maduro), exemplifica as curvas obtidas. Na Tabela 2, estão mostradas as equações de regressão das curvas, podendo ser verificada ampla variação nos valores de inclinação das retas. Tomando-se por princípio que a inclinação da reta, resultado da leitura de densidade óptica em função da concentração de um dado tipo de LBrAc, fornece indicativo da qualidade da mesma, pode-se inferir que, além das diferenças entre ligninas provenientes de diferentes espécies botânicas, há também diferenças entre ligninas oriundas de plantas jovens ou maduras, sugerindo a ocorrência de modificações na estrutura da lignina, à medida que a planta amadurece. JUNG e VOGEL (1986) mostraram que razão entre a porção interna e externa da lignina (core to non-core lignin ratio) é dependente da idade da planta. É possível que a supracitada alteração estrutural, em função do grau de maturidade da planta, também esteja relacionada com o declínio da digestibilidade da parede celular.

Ainda na Figura 1, pode-se visualizar que, no geral, os pontos da curva da lignina brometo de acetila da aveia no estádio vegetativo maduro (gráfico B) foram superiores aos pontos da curva da lignina brometo de acetila da aveia no estádio vegetativo jovem (gráfico A), empregando-se sempre as mesmas concentrações de LBrAc, ou seja, a lignina proveniente de forrageira madura absorveu com maior intensidade a luz ultravioleta em relação à lignina extraída da planta mais jovem. Em conseqüência, esta obser- 
Tabela 2 - Sumário das equações de regressão obtidas a partir das curvas -padrão das ligninas brometo de acetila ${ }^{1}$

Table 2 - Summary of regression equations obtained from the standard curves of acetyl bromide lignins ${ }^{1}$

\begin{tabular}{lcc}
\hline Amostra & Est & $\mathrm{X}=\left(\mathrm{Y}^{\prime}-\mathrm{b}\right) / \mathrm{a}$ \\
Sample & Sta & $\mathrm{X}=\left(\mathrm{Y}^{\prime}+0,000\right) / 10,83$ \\
\hline Alfafa & $\mathrm{J}$ & $\mathrm{X}=\left(\mathrm{Y}^{\prime}+0,002\right) / 13,59$ \\
Alfalfa & $Y$ & \\
& $\mathrm{M}$ & $\mathrm{X}=\left(\mathrm{Y}^{\prime}-0,046\right) / 14,09$ \\
Aveia & $\mathrm{J}$ & $\mathrm{X}=\left(\mathrm{Y}^{\prime}-0,009\right) / 19,73$ \\
Oats & $Y$ & \\
& $\mathrm{M}$ & $\mathrm{X}=\left(\mathrm{Y}^{\prime}+0,018\right) / 12,80$ \\
Braquiária & $\mathrm{J}$ & $\mathrm{X}=\left(\mathrm{Y}^{\prime}+0,008\right) / 15,11$ \\
Signal grass & $\mathrm{J}$ & \\
& $\mathrm{M}$ & $\mathrm{X}=\left(\mathrm{Y}^{\prime}+0,002\right) / 14,22$ \\
Colonião & $M$ & $\mathrm{X}=\left(\mathrm{Y}^{\prime}-0,0033\right) / 21,78$ \\
Guinea grass & $\mathrm{J}$ & $\mathrm{X}=\left(\mathrm{Y}^{\prime}+0,009\right) / 15,84$ \\
& $\mathrm{M}$ & $\mathrm{X}=\left(\mathrm{Y}^{\prime}-0,022\right) / 18,66$ \\
Eucalipto & $M$ & \\
Eucalyptus & - &
\end{tabular}

1 Est-estádio de maturidade; J-jovem; $\mathrm{M}$ - maduro; $\mathrm{X}$-concentração de lignina $(\mathrm{mg} / \mathrm{mL}) ; \mathrm{Y}^{\prime}$ - absorbância; b - intersecção da reta; a - inclinação da reta.

1 Sta - maturity stage; $Y$ - young; $M$ - mature; $X$ - lignin concentration ( $\mathrm{mg} / \mathrm{mL})$; $Y^{\prime}$ - absorbance; $b$ - intercept; $a$ - slope.

vação refletiu na constatação de que as inclinações das retas também foram diferentes entre as diversas LBrAc. Portanto, aparentemente, o grau de amadurecimento da planta influi na deposição dos monômeros fenólicos na molécula de lignina.

As concentrações de lignina nos materiais vegetais, obtidas pelos três métodos, estão mostradas na Tabela 3. O teste estatístico " $t$ " de Student indicou que não houve concordância entre os métodos de mensuração da lignina; os valores de LSBA foram mais elevados que os apresentados pelos outros dois métodos $(\mathrm{P}<0,05)$, à exceção da LDA para o pinheiro. É amplamente reconhecida a influência da maturidade sobre o teor de lignina em plantas forrageiras (VAN SOEST, 1994); nesta pesquisa, todos os três métodos analíticos mostraram forrageiras maduras exibindo concentrações mais elevadas de lignina que as plantas mais jovens, entretanto, o método LSBA apresentou praticamente os mesmos teores de lignina entre as braquiárias jovem e madura. Como as metodologia da extração da lignina pelo brometo de
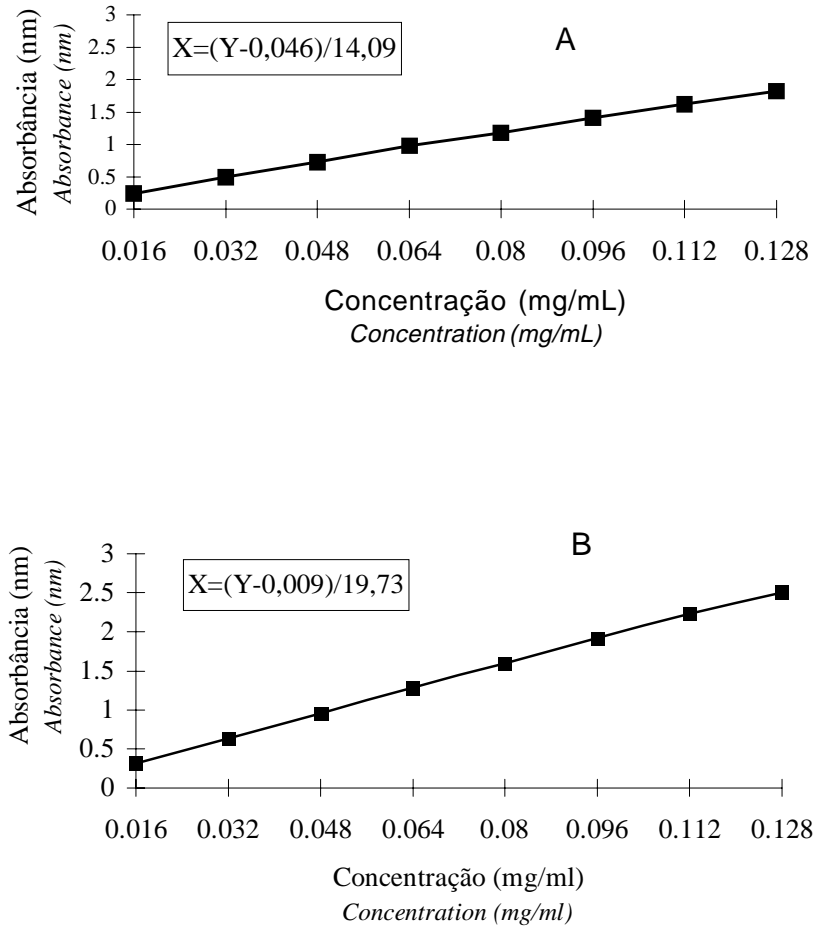

X - Concentração; Y - Absorbância

$X$ - Concentration; $Y$ - Absorbance

Figura 1 - Curvas-padrão das ligninas brometo de acetila da aveia jovem (A) e aveia madura (B).

Figure 1 - Standard curves for acetyl bromide lignins from young oats $(A)$ and mature oats $(B)$.

acetila e seu subseqüente emprego como padrão de referência ainda encontram-se em fase experimental, recomenda-se que os valores de lignina assim obtidos sejam encarados com a devida reserva. A razão LSBA/LDA variou de 0,91 a 5,51 , enquanto a razão $\mathrm{LSBA} / \mathrm{LPer}$, de 1,12 a 3,39. SHIMOJO e GOTO (1987) reportaram que a concentração de lignina em algumas forrageiras tropicais variou de 5,4 a $14,1 \%$ (LSBA) e de 3,0 a $10,2 \%$ (LDA). A razão LSBA/LDA variou de 1,73 a 2,85 para diversas forrageiras, jovens ou maduras, de trigo, centeio e arroz, cujos teores de LDA foram de 2,2 a $11,2 \%$; as concentrações de LSBA ficaram entre 6,1 e 16,7\% (IIYAMA e WALLIS, 1990).

Assim, o presente trabalho também mostrou dados superiores de lignina, quando as amostras vegetais foram estimadas pelo procedimento da LSBA, em relação às outras duas técnicas de avaliação quantitativa da lignina. O método espectrofotométrico poderia ser sensível o suficiente para detectar aqueles componentes fenólicos que seriam rapidamente 
1308 Rev. bras. zootec.

Tabela 3 - Concentrações de lignina obtidos por três métodos de mensuração da lignina e razão entre os métodos e os coeficientes de correlação entre métodos e valores de digestibilidade in vitro ${ }^{1}$

Table 3 - Concentration of lignin obtained by three methods for lignin measurement; ratio among methods and coefficients of correlation among methods and in vitro disappearance data ${ }^{1}$

\begin{tabular}{|c|c|c|c|c|c|c|c|}
\hline $\begin{array}{l}\text { Amostra } \\
\text { Sample }\end{array}$ & $\begin{array}{l}\text { Est } \\
\text { Sta }\end{array}$ & $\begin{array}{l}\text { LDA (\%) } \\
A D L(\%)\end{array}$ & $\begin{array}{l}\text { Lper }(\%) \\
\text { PerL }(\%)\end{array}$ & $\begin{array}{l}\text { LSBA }(\%) \\
A B S L(\%)\end{array}$ & $\begin{array}{c}\text { LSBA/LDA } \\
A B S L / A D L\end{array}$ & $\begin{array}{c}\text { LSBA/Lper } \\
\text { ABSL/PerL }\end{array}$ & $\begin{array}{l}\text { DIVMS (\%) } \\
\text { IVDMD (\%) }\end{array}$ \\
\hline \multirow{2}{*}{$\begin{array}{l}\text { Alfafa } \\
\text { Alfalfa }\end{array}$} & $\mathrm{J}$ & 4,4 & 9,9 & 11,1 & 2,52 & 1,12 & 67,7 \\
\hline & $\begin{array}{c}Y \\
\mathrm{M} \\
M\end{array}$ & 7,9 & 13,1 & 15,3 & 1,94 & 1,17 & 57,9 \\
\hline \multirow[t]{2}{*}{$\begin{array}{l}\text { Aveia } \\
\text { Oats }\end{array}$} & $\begin{array}{l}\mathrm{J} \\
Y\end{array}$ & 2,8 & 4,3 & 11,9 & 4,25 & 2,77 & 51,8 \\
\hline & $\begin{array}{l}\mathrm{M} \\
M\end{array}$ & 5,8 & 8,4 & 16,8 & 2,90 & 2,00 & 44,3 \\
\hline \multirow[t]{2}{*}{$\begin{array}{l}\text { Braquiária } \\
\text { Signal grass }\end{array}$} & $\begin{array}{l}\mathrm{J} \\
Y\end{array}$ & 3,5 & 5,7 & 19,3 & 5,51 & 3,39 & 45,8 \\
\hline & $\begin{array}{l}\mathrm{M} \\
M\end{array}$ & 7,5 & 8,2 & 19,4 & 2,59 & 2,37 & 25,7 \\
\hline \multirow{2}{*}{$\begin{array}{l}\text { Colonião } \\
\text { Guinea grass }\end{array}$} & $\mathrm{J}$ & 3,8 & 6,9 & 15,6 & 4,11 & 2,26 & 50,2 \\
\hline & $\begin{array}{l}Y \\
\mathrm{M} \\
M\end{array}$ & 11,4 & 13,8 & 18,5 & 1,62 & 1,34 & 27,0 \\
\hline $\begin{array}{l}\text { Eucalipto } \\
\text { Eucalyptus }\end{array}$ & - & 17,9 & 25,1 & 29,9 & 1,67 & 1,19 & 7,3 \\
\hline $\begin{array}{l}\text { Pinheiro } \\
\text { Pine tree }\end{array}$ & - & 31,6 & 24,6 & 28,6 & 0,91 & 1,16 & 6,0 \\
\hline $\begin{array}{l}\text { Média } \\
\text { Mean }\end{array}$ & - & 9,7 & 12,0 & 18,6 & - & - & 38,4 \\
\hline $\begin{array}{l}\text { Desvio-padrão } \\
\text { Standard deviation }\end{array}$ & - & 8,74 & 7,23 & 6,18 & - & - & 20,55 \\
\hline $\begin{array}{l}\text { Coeficiente correlação } \\
\text { Coefficient of correlation }\end{array}$ & - & $-0,813$ & $-0,760$ & $-0,930$ & - & - & - \\
\hline
\end{tabular}

1 Est - estádio de maturidade; J - jovem; M - maduro; LDA - lignina em detergente ácido; LPer - lignina permanganato de potássio; LSBA lignina solúvel em brometo de acetila; LSBA/LDA - razão entre os valores de LSBA e LDA; LSBA/LPer - razão entre os valores de LSBA e LPer; DIVMS - digestibilidade in vitro da matéria seca.

1 Sta - maturity stage; Y-young; $M$ - mature; ADL - acid detergent lignin; PerL - permanganate lignin; ABSL -acetyl bromide soluble lignin; ABSL/ADL - ratio between $A B S L$ and $A D L$ concentrations; $A B S L / P e r L$ - ratio between ABSL and PerL concentrations; IVDMD - in vitro dry matter disappearance.

removidos pela solução de ácido sulfúrico a $72 \%$ (FAHEY JR. et al., 1979). A superioridade numérica da LSBA foi de menor magnitude em relação à LPer; se de um lado os dados de LDA podem estar subestimados, por outro, valores de LPer devem ser encarados criteriosamente, uma vez que tanto a celulose como a hemicelulose podem ser atacadas pela solução de permanganato, particularmente em gramíneas imaturas (VAN SOEST e WINE, 1968). BARTON e AKIN (1977) mostraram que parte da hemicelulose e de alguns tecidos do mesófilo da Festuca sp foi removida pela solução de permanganato.

A técnica da LDA exibiu, à exceção do pinheiro, menores valores que o método da LPer $(\mathrm{P}<0,05)$. VAN SOEST e WINE (1968) já haviam feito observação semelhante para outras espécies vegetais e hipotetizaram que o método LPer pode refletir valo- res mais próximos do real. REBOLÉ et al. (1994) também verificaram que, para diversos tipos vegetais, a técnica da LPer forneceu teores numericamente superiores ao do procedimento da LDA. O método LDA apresenta sérios entraves - um deles é medir cutina como lignina (GOERING e VAN SOEST, 1970; FUKUSHIMA e DEHORITY, 1995), ou ainda que certa porção indefinida da lignina pode ser solúvel na solução de detergente ácido (SHIMOJO e GOTO, 1984) ou solúvel na solução concentrada de ácido sulfúrico (CRAWFORD et al., 1980; HATFIELD et al., 1994).

Os valores da digestibilidade in vitro da matéria seca constam da Tabela 3. Como seria de se esperar, o desaparecimento da matéria seca foi de maior grandeza naquelas amostras de plantas jovens $(\mathrm{P}<0,05)$, o que pode ser explicado pelo aumento da 
concentração de lignina, à medida que a planta forrageira amadurece (DEHORITY e JOHNSON, 1961; JUNG e VOGEL, 1986). Entretanto, a presente pesquisa mostrou um dado aparentemente discrepante e novamente relacionado à braquiária, que, mesmo apresentando valores de LSBA praticamente idênticos quanto ao estádio de maturidade, exibiu índices de digestibilidade in vitro da matéria seca completamente diferentes entre as forrageiras jovem e madura. Mesmo levando-se em consideração que as pesquisas focando o valor nutritivo de plantas forrageiras têm, geralmente, dado particular ênfase à concentração de lignina, associando-a com a queda na digestibilidade (VAN SOEST, 1994), e embora JUNG (1989) tenha sugerido que a composição da porção interna da lignina, e não apenas a quantidade da mesma, pode ter decisiva influência na digestibilidade da fibra, aparentemente a explicação mais plausível para a supracitada discrepância ainda reside no fato de a técnica analítica proposta no presente trabalho ser nova, necessitando de maiores estudos.

Estes dados de digestibilidade foram correlacionados com os teores de lignina obtidos pelos três procedimentos (Tabela 3 e Figura 2), embora a correlação seja um critério às vezes insatisfatório, ela reflete a praticidade de se obterem estimativas do valor nutritivo a partir da composição bromatológica (VAN SOEST e ROBERTSON, 1980). VAN SOEST (1994) mencionou que equações de regressão variam na dependência do método químico empregado, descrevendo então uma equação para a LDA e outra para a LPer. No presente experimento, a melhor correlação foi a observada para o método LSBA. É possível que o método em pauta possa ser melhor estimador da digestibilidade (ou do valor nutritivo do vegetal) que os outros dois procedimentos; entretanto, muitos outros ensaios deverão ser conduzidos, variando o número de espécies botânicas e aumentando o tamanho das amostragens.

Apesar da possível presença de diferenças intrínsecas entre as ligninas provenientes de plantas de espécies botânicas diversas, bem como a influência do estádio de maturidade, foram realizados estudos, para outro grupo de plantas forrageiras, no sentido de verificar a exequibilidade de se empregar a equação de regressão obtida para a curva de calibração da alfafa (tanto a planta jovem como a madura) para o cálculo da concentração de lignina em outras forrageiras. Os valores de LSBA calculados com
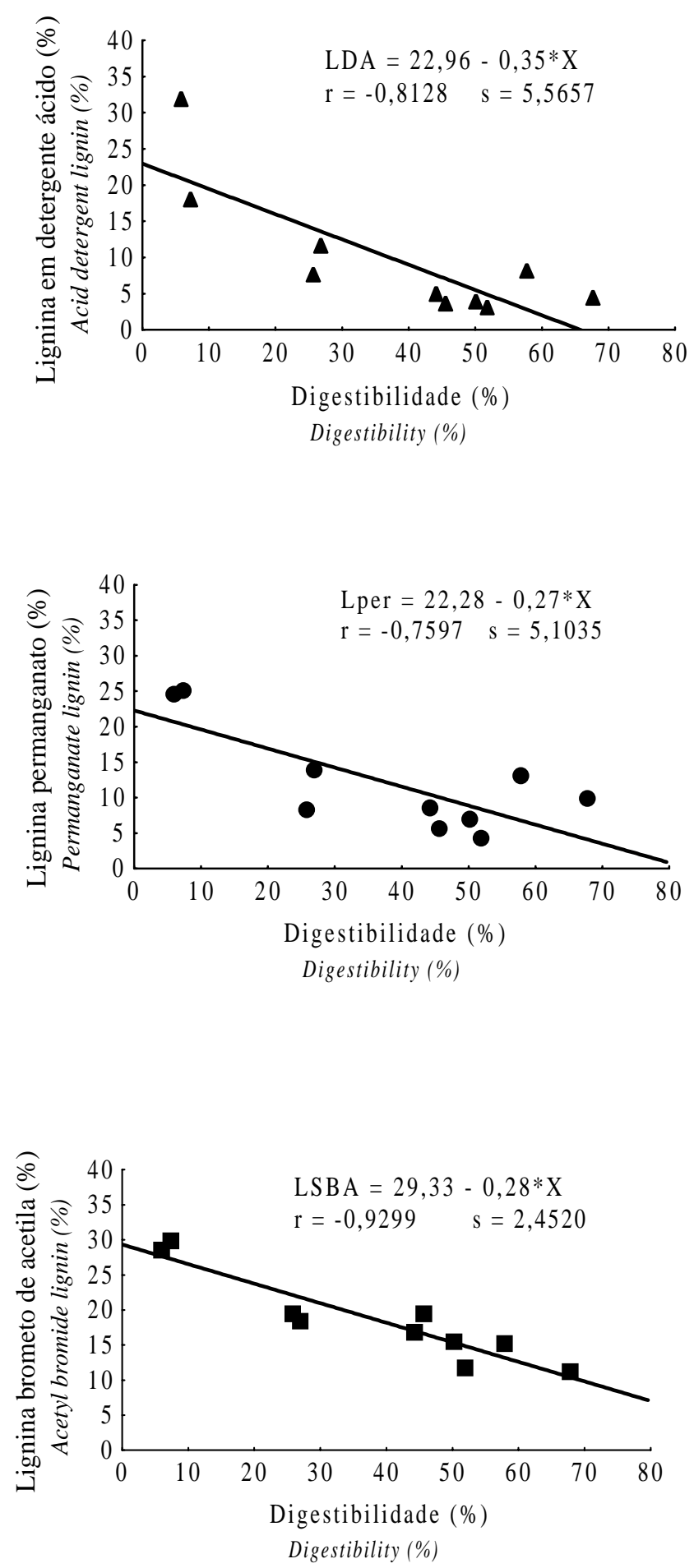

$X=$ digestibilidade; ${ }^{*}=$ sinal de multiplicação; $r=$ coeficiente de correlação; $\mathrm{s}=$ desvio-padrão.

$X=$ digestibility; ${ }^{*}=$ multiplication symbol; $r=$ correlation coefficient; $s=$ standard deviation.

Figura 2 - Curvas de regressão linear entre métodos para a mensuração da lignina e valores de digestibilidade in vitro.

Figure 2 - Linear regression curves between analytical method to quantify lignin and in vitro disappearance data. 
1310 Rev. bras. zootec.

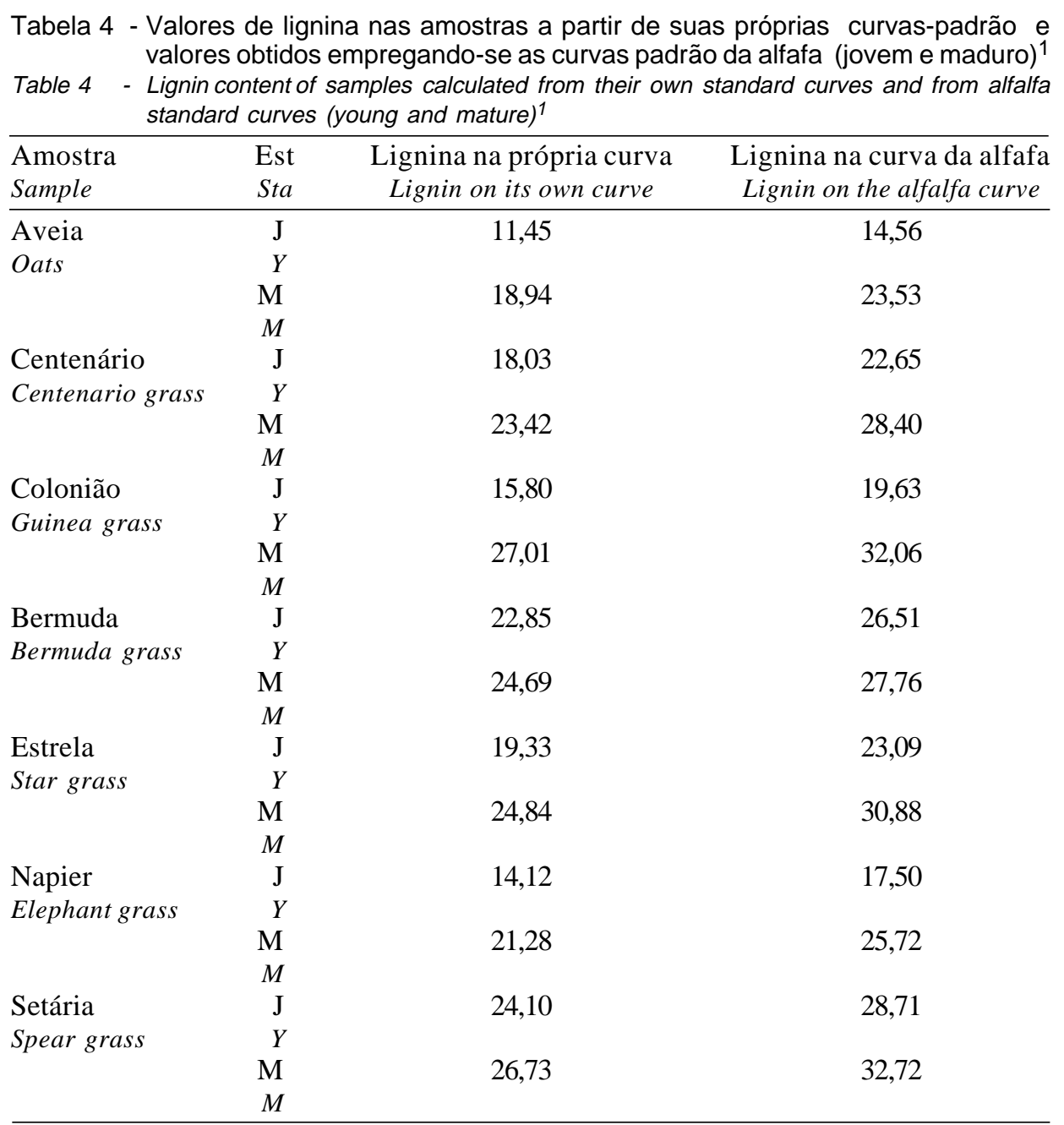

1 Valores em porcentagem; Est - estádio de maturidade; $\mathrm{J}$ - jovem; $\mathrm{M}$ - maduro.

1 Values in percentage; Sta - maturity stage; $Y$ - young; $M$ - mature.

base na curva padrão da própria planta foram de 12 a $27 \%$ menores que os obtidos por meio das curvas válidas para a alfafa (Tabela 4); portanto, a julgar pelos resultados observados, exceto à luz de novas descobertas, aparentemente inviabiliza-se a interpolação de dados entre distintas curvas padrão.

\section{Conclusões}

A extração da lignina de produtos vegetais empregando o reagente brometo de acetila e a utilização desta como padrão de referência na análise espectrofotométrica para a determinação quantitativa da lignina mostrou ótimo potencial; entretanto, ressalve-se novamente que a metodologia aqui apresentada ainda se encontra nos seus primórdios, necessitando ainda de vários estudos, objetivando esclarecer diversos aspectos obscuros e consolidar (ou não!) sua validade como técnica analítica para a quantificação do teor de lignina em produtos vegetais.

A utilização desta técnica reforçou a tese de que existem diferenças qualitativas entre as ligninas de diversas espécies botânicas. As curvas de regressão, bem como os espectrogramas obtidos, sugerem a existência de diferenças qualitativas entre as ligninas provenientes de plantas em diferentes estádios de maturidade.

A melhor correlação entre método analítico e digestibilidade in vitro foi com a metodologia proposta no presente trabalho, e, à luz de novas pesquisas, pode sugerir que esta técnica analítica é adequada para estimar a concentração de lignina em plantas forrageiras e, possivelmente, o valor nutritivo das mesmas. 


\section{Referências Bibliográficas}

ASSOCIATION OF OFICIAL ANALYTICAL CHEMISTS AOAC, 1990. Official methods of analysis. $15 \mathrm{ed}$. Washington D.C. $1298 \mathrm{p}$.

BALOGH, D.T., CURVELO, A.A.S., GROOTE, R.A.M.C. Solvent effect on organosolv lignin from Pinus caribaea hondurensis (part I). In: BRAZILIAN SYMPOSIUM ON THE CHEMISTRY OF LIGNINS AND OTHER WOOD COMPONENTS, 1, 1989, São Carlos. Proceedings... São Carlos: Universidade de São Paulo, 1989, p.313-320.

BARTON, F.E., AKIN, D.E. 1977. Digestibility of delignified forage cell walls. J. Agric. Food Chem., 25:1299.

CRAWFORD, R.L., ROBINSON, L.E., CHEH, A.M. 1980. ${ }^{14} \mathrm{C}$-labeled lignins as substrates for the study of lignin biodegradation and transformation. In: KIRK, T.K., HIGUCHI, T., CHANG, H. (Eds.) Lignin biodegradation: microbiology, chemistry, and potential applications. Boca Raton: CRC Press, v.1, p.61-76.

CURVELO, A.A.S. Organosolv lignins from Pinus caribaea hondurensis. In: BRAZILIAN SYMPOSIUM ON THE CHEMISTRY OF LIGNINS AND OTHER WOOD COMPONENTS, 2, 1992, Campinas. Proceedings... Campinas: Universidade Estadual de Campinas, 1992, p.44-55.

DARVILL, A., McNEIL, M., ALBERSHEIM, P. et al. 1980. The primary cell wall of flowering plants. In: TOLBERT, N.E. (Ed.) The biochemistry of plants (Vol. 1 The plant cell). New York: Academic Press. p.91-162.

DEHORITY, B.A., JOHNSON, R.R. 1961. Effect of particle size upon the in vitro cellulose digestibility of forages by rumen bacteria. J. Dairy Sci., 44:2242.

FAHEY JR., G.C., McLAREN, G.A., WILLIAMS, J.E. 1979. Lignin digestibility by lambs fed both low quality and high quality roughages. J. Anim. Sci., 48:941.

FENGEL, D., WEGENER, G. 1989. Wood - chemistry, ultrastructure, reactions. Berlin: Walter de Gruyter. 613p.

FUKUSHIMA, R.S. Modification of a colorimetric analysis for lignin and its use in studying the inhibitory effect of lignin on forage digestion by ruminal microorganisms. Columbus, OH: OSU. 125p. Thesis (Ph.D. in Animal Nutrition) - The Ohio State University, 1989.

FUKUSHIMA, R.S., DEHORITY, B.A., LOERCH, S.C. 1991. Modification of a colorimetric analysis for lignin and its use in studying the inhibitory effect of lignin on forage digestion by rumen microorganisms. J. Anim. Sci., 69:295.

FUKUSHIMA, R.S., DEHORITY, B.A. Acetyl bromide lignin as a standard for lignin analyses. J. Anim. Sci. (prelo)

GOERING, G.K., VAN SOEST, P.J. 1970. Forage fiber analysis (apparatus, reagents, procedures and some applications). United States Department of Agriculture (Agr. Handbook n. 379). 20p.

HATFIELD, R.D., JUNG, H.G., RALPH, J. et al. 1994. A comparison of the insoluble residues produced by the klason lignin and acid detergent lignin procedures. J. Sci. Food Agric., 65:51.

IIYAMA, K., WALLIS, A.F.A. 1990. Determination of lignin in herbaceous plants by an improved acetyl bromide procedure. J. Sci. Food Agric., 51:145.

JUNG, H.G. 1989. Forage lignins and their effects on fiber digestibility. Agron. J., 81:33.

JUNG, H.G., VOGEL, K.P. 1986. Influence of lignin on digestibility of forage cell wall material. J. Anim. Sci., 62:1703.

McDOUGALL, G.L., MORRISON, I.M., STEWART, D. et al. 1996. Plant cell walls as dietary fibre: range, structure, processing and function. J. Sci. Food Agric., 70:133.

MORRISON, I.M. 1972. A semi-micro method for the determination of lignin and its use in predicting the digestibility of forage crops. J. Sci. Food Agric., 23:455.

MORRISON, I.M. 1973. Isolation and analysis of lignincarbohydrate complexes from Lolium multiflorum. Phytochemistry, 12:2979.

REBOLÉ, A., ALVIRA, P., GONZÁLEZ, G. 1989. Variation of chemical composition data of agricultural and forest fibrous by-products as determined by the two detergent systems of analysis. J. Sci. Food Agric., 48:141-153.

ROSSINI, E.L., OLIVEIRA, M.R.G., CURVELO, A.A.S. et al. Lignins extracts by organic solvents: an extension of Brauns lignin. In: BRAZILIAN SYMPOSIUM ON THE CHEMISTRY OF LIGNINS AND OTHER WOOD COMPONENTS, 1, 1989, São Carlos. Proceedings... São Carlos: Universidade de São Paulo, 1989, p.305-312.

SHIMOJO, M., GOTO, I. 1984. A study on the relation between disappearance of dry matter and acetyl bromide lignin of tropical grass. Jpn. J. Zootechn. Sci., 55:838.

SHIMOJO, M., GOTO, I. 1987. A study on the relation between organic matter disappearance and acetyl bromide lignin of tropical forages. Jpn. J. Zootech. Sci., 58:750.

STATISTICAL ANALYSIS SYSTEM INSTITUTE INC. 1985. SAS user's guide: statistics. 5 ed, Cary: SAS Institute. 956p.

STEEL, G.D., TORRIE, J.H. 1980. Principles and procedures of statistics. New York: McGraw-Hill Book Co. 633p.

VAN SOEST, P.J. 1963. Use of detergents in the analysis of fibrous foods. II. A rapid method for the determination of fibre and lignin. J. Assoc. Off. Anal. Chem., 46:829.

VAN SOEST, P.J. 1994. Nutritional ecology of the ruminant. Ithaca: Cornell University Press. 476p.

VAN SOEST, P.J., WINE, R.H. 1968. The determination of lignin and cellulose in acid-detergent fibre with permanganate. J. Assoc. Off. Anal. Chem., 52:780.

VAN SOEST, P.J., ROBERTSON, J.B. 1980. Systems of analysis for evaluating fibrous feeds. In: PIGDEN, W.J., BALCH, C.C., GRAHAM, M. (Eds.) Standardization of analytical methodology for feeds. Ottawa: International Development Research Center. p.49-60.

VILES JR., F.J., SILVERMAN, L. 1949. Determination of starch and cellulose with anthrone. Anais. Chem. 21:950.

WHITMORE, F.W. 1982. Lignin-protein complex in cell walls of Pinus elliotti: amino acid constituents. Phytochemistry, 21:315-318.

WILSON, L.G., FRY, J.C. 1986. Extensin - a major cell wall glycoprotein. Plant Cell Environ., 9:239.

Recebido em: 06/11/98

Aceito em: 03/04/00 